\title{
Protective effects of phenolic constituents from Cytisus multiflorus, Lamium album L. and Thymus citriodorus on liver cells
}

\author{
Olívia R. Pereira ${ }^{a, b}$, Rocio I.R. Macias ${ }^{c}$, María J. Perez ${ }^{c, d}$, Jose J.G. Marin ${ }^{c, *}$, \\ Susana M. Cardoso ${ }^{b, e, *}$ \\ ${ }^{a}$ Departamento de Tecnologias de Diagnóstico e Terapêutica, Escola Superior de Saúde, Instituto Politécnico de Bragança, Av. D. Afonso V, \\ 5300-121 Bragança, Portugal \\ ${ }^{\mathrm{b}}$ CIMO, Escola Superior Agrária, Instituto Politécnico de Bragança, Campus de Santa Apolónia, 5301-855 Bragança, Portugal \\ ${ }^{\mathrm{C}}$ Laboratory of Experimental Hepatology and Drug Targeting (HEVEFARM), Biomedical Research Institute of Salamanca (IBSAL), CIBERehd, \\ University of Salamanca, Spain \\ ${ }^{d}$ Hospital Universitario de Salamanca, Instituto de Estudios de Ciencias de la Salud de Castilla y León, Salamanca, Spain \\ ${ }^{e}$ CERNAS, Escola Superior Agrária, Instituto Politécnico de Coimbra, Bencanta, 3040-316 Coimbra, Portugal
}

\section{A R T I C L E I N F O}

Article history:

Received 28 January 2013

Received in revised form

15 March 2013

Accepted 20 March 2013

Available online 13 April 2013

Keywords:

Cytisus multiflorus

Lamium album L.

Thymus citriodorus

Phenolic compounds

Cytoprotection

Antioxidant activity

\begin{abstract}
A B S T R A C T
The present study investigated the antioxidant and cytoprotective effects of purified ethanolic extracts of Cytisus multiflorus, Lamium album L. and Thymus citriodorus plants. These extracts showed high antioxidant activity in DPPH and reducing power assays. Using a model of chemical stress induced by potassium dichromate (DK) in human hepatoblastoma HepG2 cells, $50 \mu \mathrm{g} / \mathrm{mL}$ of C. multiflorus, L. album and T. citriodorus extracts decreased the rate of reactive oxygen species (ROS) production by $35 \%, 26 \%$ and $20 \%$, respectively, when exposed to $25 \mu \mathrm{M}$ of DK. This effect was also observed for the treatment of cells with individual polyphenolic compounds determined in the extracts, or with mixtures prepared with individual polyphenolic compounds simulating the phenolic composition of the extracts. Additionally, the purified ethanolic extracts and the prepared polyphenolic mixtures showed a cytoprotective effect against DK-induced toxicity. The overall results emphasize the contribution of polyphenols in antioxidant and cytoprotective properties of the studied plants.
\end{abstract}

(c) 2013 Elsevier Ltd. All rights reserved.

\section{Introduction}

Reactive oxygen species (ROS) are generated in a variety of intracellular processes and in particular in the mitochondrial electron transport chain, where the redox complexes donate electrons to oxygen leading to the formation of $\mathrm{O}_{2}^{-}$, a precursor of the majority of ROS. The imbalance between cellular antioxidant defenses and the overproduction of ROS leads to oxidative stress. This biological condition is closely associated to aging processes and to several diseases, including cardiovascular, neurodegenerative, inflammatory diseases and cancer. In particular in liver, ROS excess can induce cell damage in lipids, proteins and DNA, inducing necrosis and apoptosis of hepatocytes, amplifying the inflammatory response

\footnotetext{
* Corresponding authors. Addresses: Department of Physiology and Pharmacology, IBSAL, Campus Miguel de Unamuno EID S-09, 37007 Salamanca, Spain. Fax: +34 923294669 (J.J.G. Marin). CERNAS, Escola Superior Agrária, Instituto Politécnico de Coimbra, Bencanta, 3040316 Coimbra, Portugal. Tel.: +351 239 802940; fax: +351 273239802979 (S.M. Cardoso).

E-mail addresses: jjgmarin@usal.es (J.J.G. Marin), scardoso@esac.pt (S.M. Cardoso)

$1756-4646 / \$$ - see front matter (c) 2013 Elsevier Ltd. All rights reserved.

http://dx.doi.org/10.1016/j.jff.2013.03.014
} 
and initiating hepatic fibrosis (Sanchez-Valle, Chavez-Tapia, Uribe, \& Mendez-Sanchez, 2012).

On the other hand, plants are frequently used in traditional medicine due to their beneficial activities. Among the plant constituents, special relevance has been given to their polyphenolic compounds (PPCs), which often exhibit high antioxidant capacity and hence, are able to counteract oxidative stress (Deng et al., 2013). Polyphenols can act as antioxidants through various mechanisms, including hydrogendonating reactions, metal chelation, inhibition of cytochrome $\mathrm{P} 450$ isoforms and up-regulation or protection of antioxidant defenses (e.g. intracellular glutathione levels) (Krishnaiah, Sarbatly, \& Nithyanandam, 2011). The potential antioxidant effect of herbs, or that of isolated phenolic compounds, has been extensively determined by in vitro tests. Common methods for measuring the antioxidant capacity include free radical 2,2-diphenyl-1-picrylhydrazyl (DPPH) scavenging, $\mathrm{OH}$ radical scavenging ability, reducing/antioxidant power (FRAP), oxygen radical absorbance capacity (ORAC), and Trolox equivalence antioxidant capacity (TEAC), among others (Hossain, Patras, Barry-Ryan, Martin-Diana, \& Brunton, 2011; Jabri-Karoui, Bettaieb, Msaada, Hammami, \& Marzouk, 2012). Despite their usefulness, these assays have some limitations, the most important being the difficulty of extrapolating results to the in vivo conditions, whereas closer results can be obtained by the use of cultured cells. In this context, the HepG2 cell line, derived from human hepatoblastoma, has been extensively used as an in vitro model to investigate the beneficial potency of plant extracts with respect to hepatic injury conditions. Although these are tumour cells, they retain many of the specialized functions of normal human hepatocytes (including some which are lost by primary hepatocytes) and hence are considered as a valid tool for this type of studies (Chen, Ma, Liang, Peng, \& Zuo, 2011; Hanlon, Robbins, Hammon, \& Barnes, 2009; Wang, Lee, Chen, Yu, \& Duh, 2012). Toxicity in these cells can be induced by several agents including hydrogen peroxide, tert-butyl hydroperoxide, aflatoxin B1 and potassium dichromate (DK) (Mersch-Sundermann, Knasmuller, Wu, Darroudi, \& Kassie, 2004). The latter enters rapidly into the cells resulting in oxidative damage by means of ROS generation, lipid peroxidation, DNA breakdown and induction of apoptosis (Son et al., 2010).

Cytisus multiflorus (L'Hér.) Sweet, Lamium album L. and Thymus citriodorus are Mediterranean plants which are used, either raw or cooked, for confection of distinct local dishes. Moreover, these plants are frequently consumed in the form of tea, or in food supplements preparations (L. album L.), due to their claimed medicinal properties. Concretely, C. multiflorus has been used because of its diuretic, anti-inflammatory, anti-hypertensor and antidiabetic properties (Gião et al., 2007) while lemon thyme (T. citriodorus) has been used due to its deodorant, antiseptic and antimicrobial activities, as well as in the treatment of asthma and other respiratory diseases (Omidbaigi, Sefidkon, \& Hejazi, 2005). In turn, L. album is famous due to its antioxidant, antispasmodic, mucolytic, diuretic, haemostatic, anti-inflammatory and anticancer activities (Paduch, Wójciak-Kosior, \& Matysik, 2007).

The phenolic composition of these plants has been studied and, according to that, C. multiflorus is rich in chrysin deriva- tives (e.g. chrysin-7-O- $\beta$-D-glucopyranoside), also containing other flavones and flavonol hexoside derivatives (Pereira, Silva, Domingues, \& Cardoso, 2012a). L. album extracts mainly include the phenylpropanoid glycosides verbascoside and isoverbascoside, and some phenolic acids and flavonoids (Paduch et al., 2007; Pereira, Domingues, Silva, \& Cardoso, 2012b), while phenolic extracts of $\mathrm{T}$. citriodorus are rich in $\mathrm{O}$-glycosidic derivatives of luteolin and apigenin, as well as in rosmarinic acid (Pereira, Domingues, \& Cardoso, 2010).

The antioxidant properties of C. multiflorus (Barros, Cabrita, Boas, Carvalho, \& Ferreira, 2011) and L. album extracts (Armatu, Colceru-Mihul, Bubueanu, Draghici, \& Pirvu, 2010) have previously been evaluated by simple chemical methods (e.g. DPPH and ABTS assays) and through assessment of lipids oxidative damage. However, there are no similar assays focusing T. citriodorus extracts. Moreover, there is no available information on the ROS scavenging ability, as well as on the potential cytoprotective properties in cultured cells of C. multiflorus, $L$. album, and T. citriodorus polar extracts. This issue was investigated in the present work using a model of chemical stress induced in HepG2 cells by incubation with DK. The role of the main phenolic components of the three plant extracts on the ROS scavenging and on cytoprotective properties was also investigated in this experimental model.

\section{Experimental}

\subsection{Chemicals}

Porcine trypsin was purchased from Roche (Barcelona, Spain). Tripan blue, dimethyl sulphoxide (DMSO), "Minimum Essential Medium Eagle (MEM)" and RPMI-1640 culture media, mix of antibiotics and antimycotic, sodium piruvate, sodium bicarbonate, 3-(4,5-dimethylthiazol-2-yl)-2,5diphenyltetrazolium bromide (MTT), dichlorofluoresceindiacetate (DCFH-DA), cisplatin and DK were purchased from Sigma-Aldrich (Madrid, Spain). BHA (butylated hydroxyanisole) and DPPH radical (2,2-diphenyl-2-picrylhydrazyl) were obtained from Sigma Chemical Co. (St. Louis, MO, USA). Fetal bovine serum (FBS) was obtained from T.D.I. (Madrid, Spain). The phenolic standard compounds apigenin, chrysin, eriodictyol, quercetin, luteolin, naringenin, rosmarinic acid and verbascoside were obtained from Extrasynthese (Genay Cedex, France). Ascorbic acid was purchased from Panreac (Barcelona, Spain).

\subsection{Plant extracts}

C. multiflorus (flowers), L. album and T. citriodorus (aerial parts of both plants) were purchased from Ervital (Castro de Aire, Portugal) and the ethanolic purified extracts of the three plants were obtained and previously characterized regarding their phenolic components (Pereira et al., 2010, 2012a, $2012 b)$. The content of the main phenolics is summarized in Table 1 (in terms of aglycones and/or their derivatives) due to their relevance for the understanding of the present study. According to those studies, the total phenolic compounds in C. multiflorus, L. album and T. citriodorus purified ethanolic extracts accounted for $41 \%, 50 \%$ and $14.9 \%$ of its 
Table 1 - Mean content of phenolic compounds in Cytisus multiflorus, Lamium album and Thymus citriodorus extracts.

\begin{tabular}{|c|c|c|c|}
\hline Plant & Compound & $\begin{array}{l}\text { Mean content } \\
\text { (mg/g extract) }\end{array}$ & References \\
\hline Cytisus multiflorus & $\begin{array}{l}\text { Chrysin plus derivatives } \\
\text { Luteolin derivatives } \\
\text { Apigenin plus derivatives } \\
\text { Quercetin derivatives }\end{array}$ & $\begin{array}{l}72.8 \\
23.4 \\
20.0 \\
14.1\end{array}$ & Pereira et al. (2012a) \\
\hline Lamium album & $\begin{array}{l}\text { Verbascoside plus derivatives } \\
\text { Naringenin derivatives } \\
\text { Apigenin derivatives } \\
\text { Luteolin derivatives }\end{array}$ & $\begin{array}{l}272.9 \\
32.6 \\
32.3 \\
29.7\end{array}$ & Pereira et al. (2012b) \\
\hline Thymus citriodorus & $\begin{array}{l}\text { Luteolin derivatives } \\
\text { Rosmarinic acid plus derivative } \\
\text { Apigenin derivatives } \\
\text { Eriodictyol derivatives } \\
\text { Naringenin derivatives }\end{array}$ & $\begin{array}{l}15.2 \\
12.7 \\
9.0 \\
5.7 \\
1.8\end{array}$ & Pereira et al. (2010) \\
\hline
\end{tabular}

weight, respectively. Moreover, the phenolic composition of C. multiflorus was mainly composed of chrysin-7-O- $\beta$-Dglucopyranoside and of considerable amounts of a dihydroxyflavone isomer of chrysin. These two derivatives plus chrysin accounted for $56 \%$ of the total phenolic compounds quantified in the extract that is equivalent to $72.8 \mu \mathrm{g} / \mathrm{mg}$ extract. Moreover, luteolin derivatives (2"-O-pentosyl-6-C-hexosyl-luteolin, 2"-O-pentosyl-8-C-hexosyl-luteolin and orientin) accounted for approximately $23.4 \mu \mathrm{g} / \mathrm{mg}$ extract, while apigenin plus its derivatives and quercetin derivatives accounted for 20.0 and $14.1 \mu \mathrm{g} / \mathrm{mg}$ extract, respectively. In turn, the amount of verbascoside and its derivatives in the L. album purified ethanolic extract represented approximately $56 \%$ of the total phenolic content $(272.9 \mu \mathrm{g} / \mathrm{mg}$ extract). Remaining phenolic compounds in the extract enclosed isoscutellarein glycosides and 7-0-derivatives of naringenin, apigenin and luteolin, with the three latter accounting for 32.6, 32.3 and $29.7 \mu \mathrm{g} / \mathrm{mg}$ extract, respectively. In turn, $T$. citriodorus purified ethanolic extract mainly comprised luteolin derivatives $(15.2 \mu \mathrm{g} / \mathrm{mg}$ extract) and rosmarinic acid and derivative $(12.7 \mu \mathrm{g} / \mathrm{mg}$ extract), besides minor amounts of eriodictyol and apigenin derivatives.

\subsection{DPPH test}

The scavenging capacity of each purified ethanolic extract was carried out by DPPH radical test following the Kirby and Schmidt (1997) procedure with adaptations. For that, distinct methanolic test solutions $(0.05,0.1,0.25,0.5$ and $0.8 \mathrm{mg} / \mathrm{mL})$ of the extracts of C. multiflorus, L. album and T. citriodorus were prepared and $0.1 \mathrm{~mL}$ of each solution was added to $1.7 \mathrm{~mL}$ of a methanolic solution of DPPH $(60 \mu \mathrm{M})$ in a test tube, followed by vigorous shaken. After $30 \mathrm{~min}$ of incubation in the dark, the absorbance of the mixtures was measured in a spectrophotometer at $517 \mathrm{~nm}$, against a blank (absence of DPPH). The radical scavenging activity of each purified ethanolic extract was calculated as the percentage of DPPH discoloration, using the equation of Yen and Duh (1994):

$\% D P P H$ radical scavenging $=\left[\left(A_{C}(0)-A_{E}(t)\right) / A_{C}(0)\right]^{*} 100$, where: $A_{C}(0)=$ Absorbance of the control at $t=0 \mathrm{~min} ; A_{E}$ $(t)=$ Absorbance of the extract at $t=30 \mathrm{~min}$.
Based on graphic values of percentage of DPPH inhibition us. extract concentration, the $\mathrm{EC}_{50}$ (concentration of the extract able to inhibit the $50 \%$ of the DPPH radical) of each extract was estimated. Ascorbic acid was used as positive control.

\subsection{Reducing power test}

The ability of C. multiflorus, L. album and T. citriodorus extracts in reducing iron (III) was assessed by the method described by Barros et al. (2011), performed in a 48-well plate using an ELX800 Microplate Reader (BioTek Instruments, Inc., Winooski, VT, USA). For that, $0.5 \mathrm{~mL}$ of distinct concentrations $(0.05,0.067,0.1,0.125,0.25 \mathrm{mg} / \mathrm{mL})$ of each extract of interest was mixed with $0.5 \mathrm{~mL}$ of phosphate buffer $(0.2 \mathrm{M}, \mathrm{pH} 6.6)$ and $0.5 \mathrm{~mL}$ of a $1 \%$ potassium hexacyanoferrate $\left[\mathrm{K}_{3} \mathrm{Fe}(\mathrm{CN})_{6}\right]$ aqueous solution. After $20 \mathrm{~min}$ of incubation at $50^{\circ} \mathrm{C}, 0.5 \mathrm{~mL}$ of $10 \%$ trichloroacetic acid was added and $0.8 \mathrm{~mL}$ of the mixture was poured in the 48 -wells with $0.8 \mathrm{~mL}$ of deionized water and $0.16 \mathrm{~mL}$ of $\mathrm{FeCl}_{3}(0.1 \%, \mathrm{w} / \mathrm{v})$. The absorbance was measured at $690 \mathrm{~nm}$. The mean absorbance values were plotted against concentration, a linear regression analysis was carried out, and the $\mathrm{EC}_{50}$ value, corresponding to the extract concentration providing 0.5 of absorbance, was determined. BHA was used as positive control.

\subsection{Cell culture}

Human hepatoblastoma HepG2 cells (HB-8065) were obtained from the American Type Culture Collection (Manassas, VA, USA) and cultured in polystyrene flasks (Falcon) with MEM supplemented with $1 \mathrm{mM}$ of sodium pyruvate, $26.2 \mu \mathrm{M}$ of sodium bicarbonate, inactivated FBS $10 \%(\mathrm{v} / \mathrm{v})$ and $1 \%$ of a mixture antibiotic-antimycotic solution [penicillin $(20 \mathrm{U} / \mathrm{mL})$, streptomycin $(0.02 \mathrm{mg} / \mathrm{mL})$ and amphotericin B $(0.05 \mu \mathrm{g} / \mathrm{mL})$ ] under an atmosphere of $5 \% \mathrm{CO}_{2}$ at $37^{\circ} \mathrm{C}$. Cells were plated onto 96 well-plates at a density of $0.3 \times 10^{6}$ or $0.15 \times 10^{6}$. cells $/ \mathrm{mL}$ ( 6 or $72 \mathrm{~h}$ treatments, respectively) in a total volume of $100 \mu \mathrm{L}$, for the MTT experiments. Alternatively, cells were seeded in 6 well-plates at a density of $0.1 \times 10^{6}$ cells $/ \mathrm{mL}$, in a total volume of $2 \mathrm{~mL}$, for ROS experiments. 


\subsection{Preparation of test solutions for cellular assays}

The C. multiflorus, L. album and T. citriodorus purified ethanolic extracts were dissolved in culture medium at a concentration of $1 \mathrm{mg} / \mathrm{mL}$ and sterilized by UV light exposure ( $1 \mathrm{~h}, 30 \mathrm{~W})$, in order to avoid the contamination of the cultured cells. Phenolics stability under these conditions was confirmed by HPLCDAD analysis (data not shown). Standard compounds, namely apigenin, chrysin, eriodictyol, quercetin, luteolin, naringenin, rosmarinic acid and verbascoside, were dissolved in sterile dimethyl sulphoxide (DMSO) $(50 \mathrm{mg} / \mathrm{mL})$. These concentrated solutions were subsequently diluted in culture medium to obtain final concentrations of $1-200 \mu \mathrm{g} / \mathrm{mL}$ for purified ethanolic extracts or $50 \mu \mathrm{g} / \mathrm{mL}$ for standard compounds. The final DMSO concentration was lower than $0.5 \%$ and did not affect the cell viability or ROS production (data not shown). Based on the phenolic composition of each target purified ethanolic extract (Pereira et al., 2010, 2012a, 2012b), three mixtures of phenolic standards were also prepared taking into account the amount of the individual PPCs determined in $50 \mu \mathrm{g} / \mathrm{mL}$ of each extract. In this sense, luteolin, apigenin, quercetin and chrysin were used with final individual concentrations of $1.2,1.0,0.7,3.6 \mu \mathrm{g} / \mathrm{mL}$, respectively, for the C. multiflorus mixture. These quantities corresponded to the global amount of each aglycone (plus their derivatives) in the extract. In a similar way, the L. album PPCs mixture was prepared with the phenolic compounds verbascoside, luteolin, apigenin, naringenin with concentrations of $14.0,1.4,1.6,1.6 \mu \mathrm{g} / \mathrm{mL}$, respectively, while that of $\mathrm{T}$. citriodorus was obtained with $0.3,0.8,0.1,0.5,0.6 \mu \mathrm{g} / \mathrm{mL}$ of eriodictyol, luteolin, naringenin, apigenin and rosmarinic acid, respectively.

\subsection{Determination of cell viability by MTT assay}

Twenty-four hours after seeding the cells, the culture medium was replaced by fresh medium containing the desired concentration of agents (extracts, PPCs mixtures or individual standards) in the presence or absence of DK. After incubation for 6 or $72 \mathrm{~h}$, viability of HepG2 cells was determined by the formazan formation from tetrazolium salt (MTT) by living cells (Briz, Serrano, Macias, \& Marin, 2000). Briefly, cells were rinsed with $\mathrm{PBS}$ and incubated with $0.5 \mathrm{mg} / \mathrm{mL}$ of MTT dissolved in RPMI medium for $4 \mathrm{~h}$ at $37^{\circ} \mathrm{C}$. Cell lysis and dissolution of purple formazan crystals were accomplished by adding $100 \mu \mathrm{L}$ of SDS and further incubation overnight at $37^{\circ} \mathrm{C}$. The absorbance was read at $595 \mathrm{~nm}$ in an ELISA reader (model 550, Bio-Rad, Madrid, Spain). Cisplatin $(0.3-30 \mu \mathrm{g} / \mathrm{mL}$ ), a classic cytotoxic compound, was used as a positive control of toxicity. Cell viability was calculated as the percentage of living cells compared to untreated (control) cells. Moreover, possible unspecific reactions between MTT and the antioxidants were rejected by a control experiment performed in the presence of MTT and distinct extract/standard concentrations, in the absence of cells.

The short-term exposure $(6 \mathrm{~h})$ was used to determine acute cell toxicity while long-term exposure $(72 \mathrm{~h})$ permitted to calculate the antiproliferative effect in accordance to preestablished methods (Zakaria et al., 2011). Toxicity in those experiments were, respectively, induced by DK at 200 and $2 \mu \mathrm{M}$, since previous studies by our group have shown a de- crease on the HepG2 cells viability of about $25-45 \%$ in those conditions (data not shown).

\subsection{Determination of ROS production by flow cytometry}

After $48 \mathrm{~h}$ incubation of HepG2 cells with the desired concentration of agents and/or DK, the medium was replaced by RPMI medium containing $5 \mu \mathrm{g} / \mathrm{mL}$ of the probe DCFH-DA (a stable non-fluorescent cell permeable compound). After $30 \mathrm{~min}$, cells were trypsinized and resuspended in FBS freemedium. When internalized by the cell, DCFH-DA is hydrolyzed to DCFH by intracellular esterases and rapidly oxidized to the highly green fluorescent compound 2,7-dichlorofluorescein (DCF) by endogenous ROS, in particular hydroperoxides. ROS generation was measured and analyzed in a FACSCalibur flow cytometer (BD Biosciences, San Jose, CA, USA) and CellQuest software (BD Biosciences). The values were expressed as percentage of ROS formation by untreated cells. Note that the $48 \mathrm{~h}$ of exposure was used to investigate the effect on ROS production before the end-point used for the cell growth inhibition assays. Increment in ROS production by approximately two and three fold was accomplished by their treatment with DK at 5 and $25 \mu \mathrm{M}$, respectively.

\subsection{Statistical analysis}

Data were expressed as mean \pm S.E.M. of the number of experiments as indicated in the figure legends. The comparison between groups was performed by one-way ANOVA, followed by Dunnett's post hoc test.

\section{Results and discussion}

\subsection{Determination of the non-toxic concentration ranges of the purified extracts}

As mentioned above, the HepG2 cells are a well-known in vitro model for the assessment of protective activities of natural extracts or compounds in toxicological investigations in liver cells (Chen et al., 2011; Wang et al., 2012) and were herein used in the present study to evaluate the potential antioxidant and cytoprotective effects of C. multiflorus, L. album, and T. citriodorus purified ethanolic extracts.

As a first approach, HepG2 cells were treated with different concentrations $(1-200 \mu \mathrm{g} / \mathrm{mL})$ of purified ethanolic extracts, in order to determine the non-toxic range of doses, allowing to choose the appropriate concentrations of extracts to be used in the following experiments. This was evaluated by means of the MTT assay, an extensively used test to monitor cell survival. Our results demonstrated that the toxicity of the three extracts was very low compared to that of cisplatin, a classic cytotoxic compound. Except for T. citriodorus, the cell viability measured after $72 \mathrm{~h}$ of treatment was unaffected up to $200 \mu \mathrm{g} /$ $\mathrm{mL}$ (Fig. 1). Based on this study, the $50 \mu \mathrm{g} / \mathrm{mL}$ dose was selected for testing the ROS scavenging and cytoprotective activities of the three extracts, while that of $200 \mu \mathrm{g} / \mathrm{mL}$ was additionally selected for C. multiflorus and L. album.

Regarding the MTT assay, it is also important to note that despite some of the main aglycones from the plant extracts 


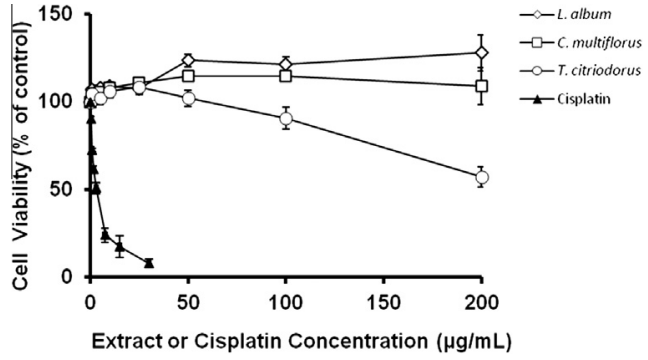

Fig. 1 - Viability of human hepatoblastoma HepG2 cells incubated with increasing concentrations of the purified ethanolic extracts from Cytisus multiflorus, Lamium album and Thymus citriodorus $(1-200 \mu \mathrm{g} / \mathrm{mL})$ for $72 \mathrm{~h}$. Cisplatin was used as a positive control of cytotoxicity in HepG2 cells. Values are means of percentage of cell viability with respect to control \pm S.E.M. from four independent experiments performed in triplicate.

have been shown to exert cytotoxic effects on HepG2 cells, e.g. chrysin, verbascoside and luteolin (Ahmed, Mohamed, El-Dib, \& Hamed, 2009; Yee et al., 2003), no toxicity was registered for the investigated phenolic enriched ethanolic extracts. Different experimental conditions (e.g. treatment period), presence of different forms of phenolic derivatives (aglycones or glycosides) in extracts or counterbalanced effects of the multiple extract components could account for this result. Besides this, it should be highlighted that the slight increment in cell viability observed after incubation with the low doses of extracts is not surprising and has been observed with other molecules with antioxidant properties, such as bile acids, at non-toxic doses (Briz et al., 2000).

\subsection{Antioxidant and cytoprotective properties of purified} ethanolic extracts and PPCs

\subsubsection{Chemical models}

The antioxidant potential of purified ethanolic extracts was first estimated by the DPPH radical scavenging and reducing power assays. These two chemical tests are widespread used for estimating the antioxidant capacity of plant extracts related to their ability to trap the DPPH radical, and to reduce $\mathrm{Fe}^{3+}$ to $\mathrm{Fe}^{2+}$, respectively. As observed in Table 2, the three purified ethanolic extracts had close DPPH EC $\mathrm{E}_{50}$ values, rang- ing from approximately 11 to $13 \mu \mathrm{g} / \mathrm{mL}$. Considering that these $\mathrm{EC}_{50}$ values are only five times lower than that obtained for ascorbic acid (Table 2), we might conclude that the purified ethanolic extracts of the three plants have a considerable DPPH scavenging ability. The DPPH scavenging ability has previously been described for $C$. multiflorus and for L. album phenolic extracts, while to the best of our knowledge this topic has not yet been addressed for T. citriodorus. In general, the $\mathrm{DPPH} \mathrm{EC}_{50}$ herein estimated were lower than those previously described, which is probably due to the extract purification step applied in the present study. Previous described DPPH $\mathrm{EC}_{50}$ values ranged from 71.5 to $2000 \mu \mathrm{g} / \mathrm{mL}$ (Barros et al., 2011; Luis, Domingues, \& Duarte, 2011) and from 30 to $466 \mu \mathrm{g} / \mathrm{mL}$ (Armatu et al., 2010; Valyova, Dimitrova, Ganeva, Mihova Kapchina-Toteva, \& Petkova Yordanova, 2011), for polar extracts of C. multiflorus and L. album, respectively.

Regarding the reducing power assay, the $\mathrm{EC}_{50}$ values obtained in the present study for C. multiflorus, L. album and T. citriodorus purified ethanolic extracts were respectively $95.7 \pm 2.7,67.9 \pm 5.0$ and $88.2 \pm 0.8 \mu \mathrm{g} / \mathrm{mL}$ (or 1.6, 2.3, $1.9 \mathrm{mmol}$ BHA/g extract, respectively). Similarly to the DPPH assay data, the present $\mathrm{EC}_{50}$ values for $\mathrm{C}$. multiflorus are much inferior to those previously reported $(410 \mu \mathrm{g} / \mathrm{mL}$ ) by other group (Barros et al., 2011). These results indicate a 2 to 3-fold less general capacity for reducing $\mathrm{Fe}^{3+}$ to $\mathrm{Fe}^{2+}$ than that of BHA, the potent synthetic antioxidant used as positive control (Table 2). The reducing capacity order was L. album $>$ T. citriodorus $>C$. multiflorus.

\subsubsection{Protective effects against ROS production and decrease} in cell viability induced by potassium dichromate in human hepatoblastoma HepG2 cells

The antioxidant capacity of the three purified ethanolic extracts was further evaluated for their ROS scavenging abilities, on the potassium dichromate-stimulated human hepatoblastoma HepG2 cell model. As observed in Fig. 2, the exposure of the cells to 5 or $25 \mu \mathrm{M}$ potassium dichromate caused a significant increase in the intracellular ROS levels, of 1.9-fold and 2.9-fold of the control, respectively. However, co-incubation of cells with potassium dichromate plus the target purified ethanolic extracts partially prevented the increase in intracellular ROS levels. This effect was dosedependent for C. multiflorus and L. album purified ethanolic extracts (Fig. 2A and B). Note that in contrast to the results ob-

Table 2 - Radical scavenging potential and reducing power of Cytisus multiflorus, Lamium album and Thymus citriodorus extract plants.

\begin{tabular}{|c|c|c|}
\hline \multirow[t]{2}{*}{ Compound/plant extract } & \multicolumn{2}{|c|}{$\mathrm{EC}_{50}(\mu \mathrm{g} / \mathrm{mL})$} \\
\hline & Radical scavenging ${ }^{A}$ & Reducing power $^{B}$ \\
\hline Ascorbic acid & $2.5 \pm 0.2^{a}$ & - \\
\hline BHA & - & $27.1 \pm 0.6^{\mathrm{c}}$ \\
\hline Cytisus multiflorus & $13.4 \pm 0.5^{b}$ & $95.7 \pm 2.7^{d}$ \\
\hline Lamium album & $11.2 \pm 0.5^{b}$ & $67.9 \pm 5.0^{\mathrm{e}}$ \\
\hline Thymus citriodorus & $11.7 \pm 1.5^{b}$ & $88.2 \pm 0.8^{d}$ \\
\hline
\end{tabular}




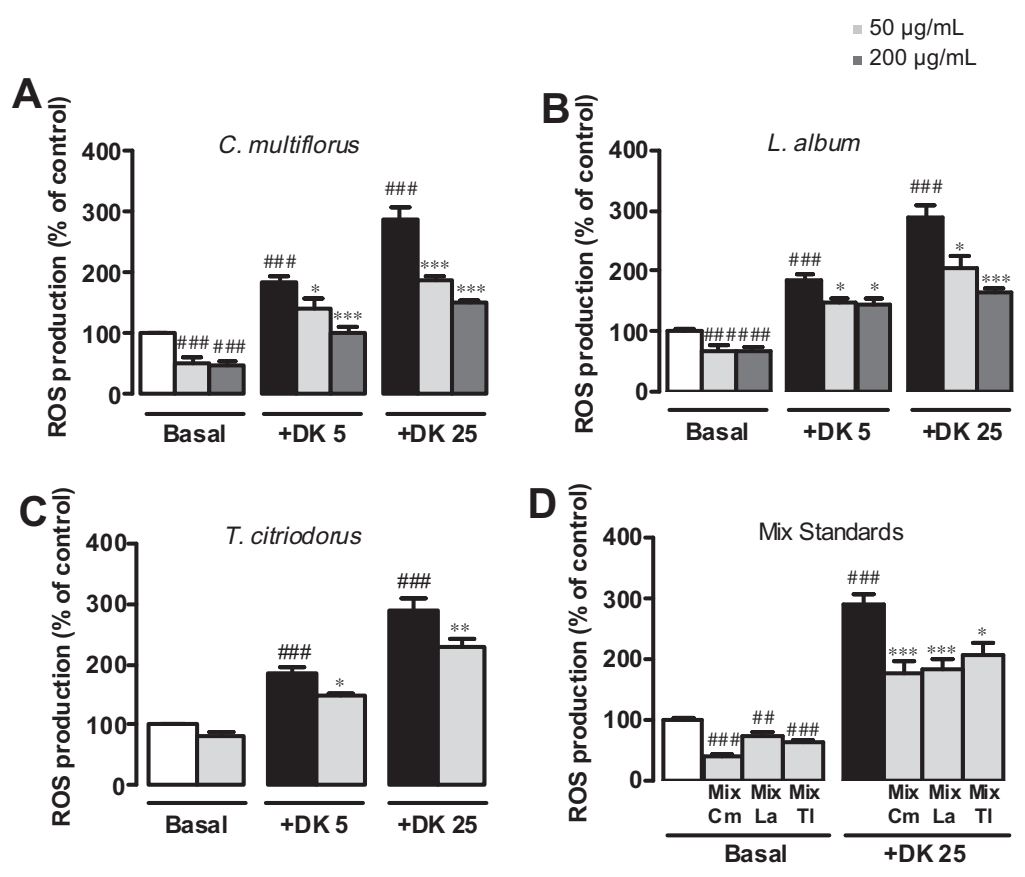

Fig. 2 - Protective effect of Cytisus multiflorus (A), Lamium album (B) and Thymus citriodorus (C) purified ethanolic extracts and mixtures of PPCs simulating each plant extract (D) on intracellular ROS production in human hepatoblastoma HepG2 cells induced with potassium dichromate (DK). Cells were incubated in the absence $(\square, \square)$ or presence of two non-toxic extract concentrations: at $50 \mu \mathrm{g} / \mathrm{mL}$ () (for all the extracts) or at $200 \mu \mathrm{g} / \mathrm{mL}$ () for Cytisus multiflorus and Lamium album extracts and with mixtures of PPCs that simulate each plant extract $(D$,$) . With the exception of the basal condition, the cells were$ exposed to DK at 5 or $25 \mu \mathrm{M}$, for $48 \mathrm{~h}$. The white columns ( $\square$ ) represent the control condition and the black columns ( $\square$ ) represent the incubation of HepG2 cells with DK alone. Values are expressed as means \pm S.E.M. of percentage of ROS production versus control, from 3-4 independent experiments performed in triplicate. Mix Cm, Cytisus multiflorus PPCs mixture; Mix La, Lamium album PPCs mixture; Mix Tc, Thymus citriodorus PPCs mixture. Statistical analysis was performed by one-way ANOVA, followed by Dunnett's post hoc test. ${ }^{*} p<0.05 ;{ }^{* *} p<0.01 ;{ }^{* * *} p<0.001$ when compared to cells exposed to 5 or

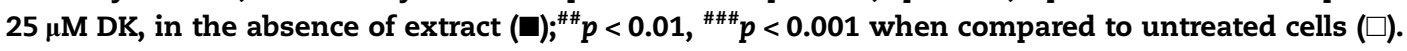

tained in the chemical models, C. multiflorus purified ethanolic extract was the most effective in counteracting the potassium dichromate-increased ROS formation. In more detail, treatment of cells with C. multiflorus, L. album or T. citriodorus extracts at $50 \mu \mathrm{g} / \mathrm{mL}$ decreased the intracellular ROS formation by about $19 \%, 23 \%$ and $21 \%$, respectively $(5 \mu \mathrm{M}$ potassium dichromate-stimulated cells) or about $35 \%, 26 \%$ and $20 \%$, respectively $(25 \mu \mathrm{M}$ potassium dichromate-stimulated cells) (Fig. 2A-C). Moreover, for both potassium dichromate treatment conditions, purified ethanolic extract from C. multiflorus $>$ L. album (both at $200 \mu \mathrm{g} / \mathrm{mL}$ ) decreased ROS production. These extracts also reduced the intracellular ROS levels at basal conditions, e.g., in the absence of potassium dichromate; C. multiflorus (47-53\%), L. album ( $\approx 30 \%)$ and $\mathrm{T}$. citriodorus ( $\approx 15 \%$, not significant).

Overall, the results obtained in this part of the work suggested that the three purified ethanolic extracts, and in particular those of C. multiflorus and L. album can act as good ROS scavenging agents in oxidative stress conditions in hepatic cells. To the best of our knowledge, this is the first report describing the potential ROS-scavenging ability of these purified ethanolic extracts.

The purified ethanolic extracts also exhibited protection against the potassium dichromate-induced acute toxicity $(200 \mu \mathrm{M}, 6 \mathrm{~h})$ or long-term toxicity $(2 \mu \mathrm{M}, 72 \mathrm{~h})$ as measured by the MTT assay. As can be observed in Fig. 3A, under acute toxic conditions, all the purified ethanolic extracts exerted a significant protection against the cell viability decrement (about 30\%). Moreover, the C. multiflorus and L. album extracts partially prevented cell viability decrement under long-term toxic conditions (Fig. 3B). The cytoprotective effects of the individual purified ethanolic extracts $(50 \mu \mathrm{g} / \mathrm{mL})$ were not potentiated by the treatment of the cells with combinations of two extracts ( $25 \mu \mathrm{g} / \mathrm{mL}$ each), suggesting the absence of synergisms on the mentioned beneficial properties of the extracts.

In order to determine the role of PPCs in the observed protective effects of the three purified ethanolic extracts, the previous assays were performed with three PPCs mixtures prepared as described in the methods section by mixing the individual PPCs apigenin, chysin, eriodictyol, luteolin, naringenin, quercetin, rosmarinic acid and verbascoside to simulate the content determined in $50 \mu \mathrm{g} / \mathrm{mL}$ of $C$. multiflorus, L. album and T. citriodorus purified ethanolic extracts. It should be mentioned that aglycones were used instead of the glycosylated forms detected in these purified ethanolic extracts due to their commercial availability. Although some differences can be expected in the ROS scavenging capacity and in the cytoprotective activity between these two forms when tested under in vitro conditions, it is important to note that PPCs are 
A
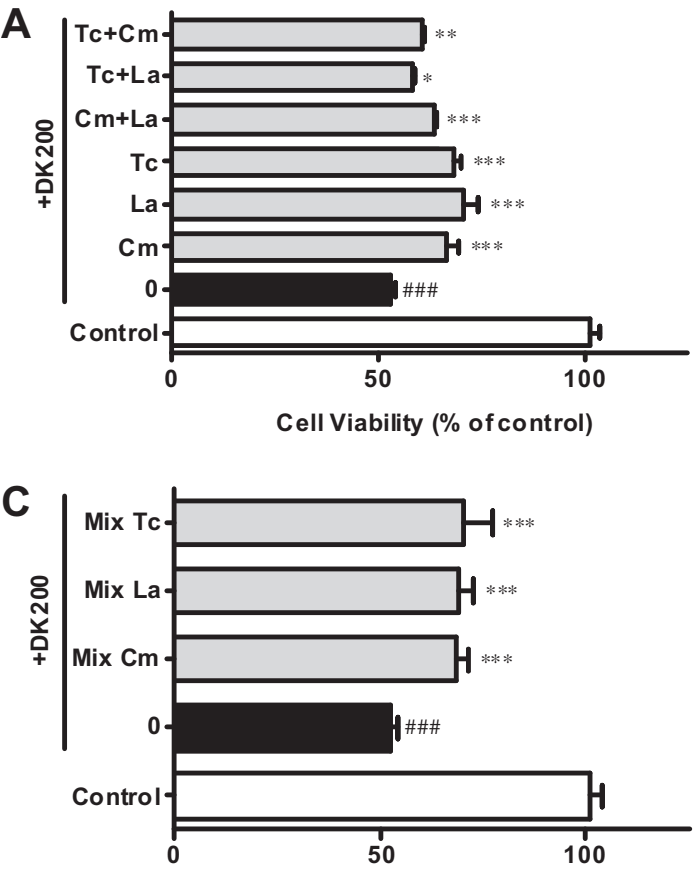

Cell Viability ( $\%$ of con trol)

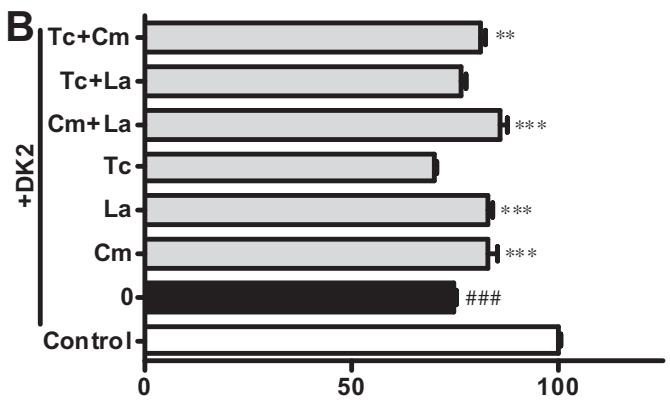

Cell Viability ( $\%$ of control)

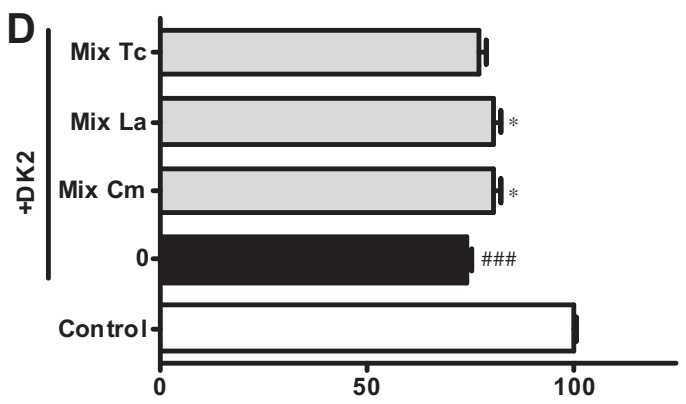

Cell Viability (\% of control)

Fig. 3 - Protective effect of Cytisus multiflorus (A), Lamium album (B) and Thymus citriodorus (C) purified ethanolic extracts and mixtures of PPCs simulating each plant extract (D) in the potassium dichromate (DK)-induced cell viability decrement of human hepatoblastoma HepG2 cells. Cells were incubated in the absence $(\square, \square)$ or presence of each extract $(50 \mu \mathrm{g} / \mathrm{mL})$ or their mixtures $(25 \mu \mathrm{g} / \mathrm{mL}$ each) (, A, B) or alternatively with mixtures of PPCs that simulate each plant extract (, C, D). With the exception of the control condition $(\square)$ the cells were then exposed to potassium dichromate (DK) $200 \mu \mathrm{M}$ for $6 \mathrm{~h}$ (A, C) or $2 \mu \mathrm{M}$ for $72 \mathrm{~h}(B, D)$. The black columns ( $\square$ ) represent the incubation of HepG2 cells with DK alone. Values are means \pm S.E.M. of percentage of cell viability versus control, from 3-4 independent experiments performed at least in triplicate. Cm, Cytisus multiflorus extract; Mix Cm, Cytisus multiflorus PPCs mixture; La, Lamium album extract; Mix La, Lamium album PPCs mixture; Tc, Thymus citriodorus extract; Mix Tc, Thymus citriodorus PPCs mixture. Statistical analysis was performed by one-way ANOVA, followed by Dunnett's post hoc test. ${ }^{*} p<0.05 ;{ }^{* *} p<0.01,{ }^{* * *} p<0.001$ when compared to cells exposed to DK ( $\square$ ), in the

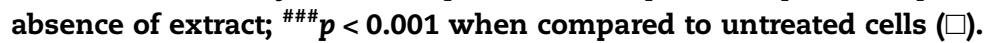

mainly absorbed in vivo as aglycones, since most classes of glycosylated PPCs are hydrolyzed in the intestine before absorption (D'Archivio et al., 2010).

As shown in Fig. 2D, a significant reduction of intracellular ROS production was observed both in basal conditions (mainly for the C. multiflorus mixture) and under co-treatment of cells with $25 \mu \mathrm{M}$ potassium dichromate and each PPCs mixture.

A similar result was observed in the MTT assay (Fig. 3C and D). The three PPCs mixtures prevented the cell viability reduction induced by short-term potassium dichromate exposure ( $\approx 32 \%$ ) (Fig. 3C), while the protection was lost after long-term incubation for the T. citriodorus mixture (Fig. 3D).

Literature data focusing on plant phenolics frequently associate their content to the health benefits, in particular with the antioxidant capacity of the extracts. This theory is valid, at least partially, in the present study. In fact, L. album extract, which is the most enriched in phenolics $(501 \mathrm{mg} / \mathrm{g}$ ), showed high antioxidant potential both in chemical models and in ROS scavenging and cytoprotective actions in potassium dichromate-exposed HepG2 cells. In turn, T. citriodorus extract, the most poor extract in phenolic compounds (149 mg/g) also presented the weakest antioxidant capacity in all the tested models and was not able to protect HepG2 cells from potassium dichromate toxicity for long incubation time $(72 \mathrm{~h})$.

This is the first study focusing on the potential antioxidant abilities and cytoprotective activities of C. multiflorus, L. album and T. citriodorus purified ethanolic extracts, as well as on the association of these beneficial effects to the main phenolic constituents of the extracts. The herein focused benefits have also been scarcely studied for plants of the three genera (Cytisus, Lamium and Thymus). To our knowledge, the antioxidant and cytoprotective effects of Cytisus scoparius plant were demonstrated by in vivo studies. Oral administration of the extract counteracted the decrease of superoxide dismutase and catalase and the increase of lipid peroxidation in a chronic unpredictable mild stress model in rats, and protected the liver from carbon tetrachloride-induced oxidative stress in rats by increasing the levels of glutathione and several antioxidant hepatic enzymes (Raja et al., 2007a, 2007b). Some of these effects have showed a good correlation with total phenolic content in the C. scoparius plant extract (Luis, Domingues, Gil, \& Duarte, 2009). Other in vivo work revealed important cytoprotective activities of Thymus vulgaris on an alcohol abuse model by reversing the reduction of the antioxidant capacity and 

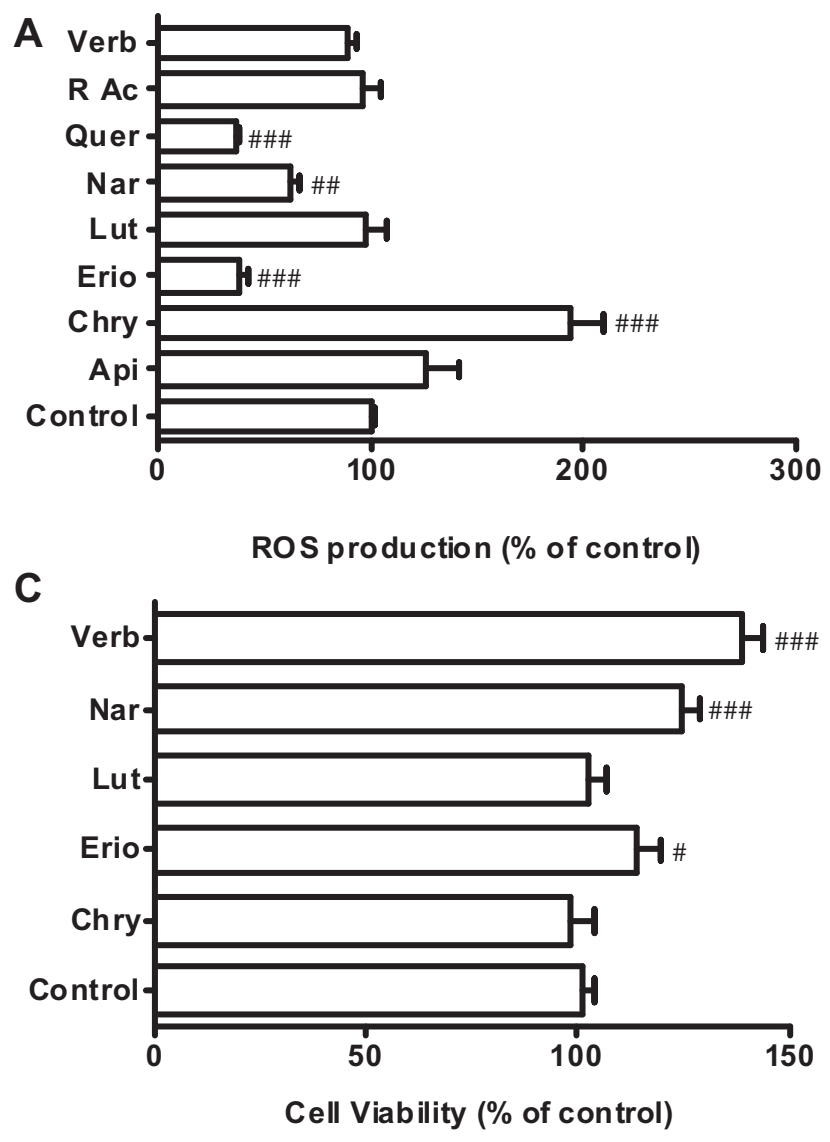

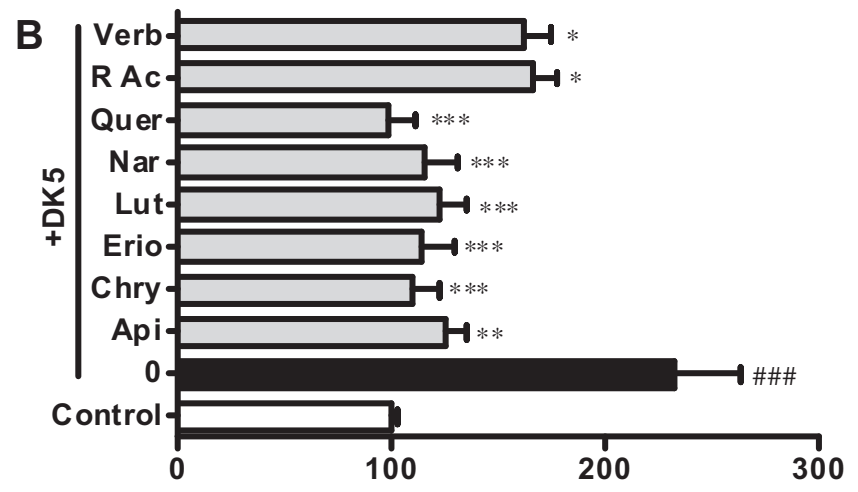

ROS production (\% of control)

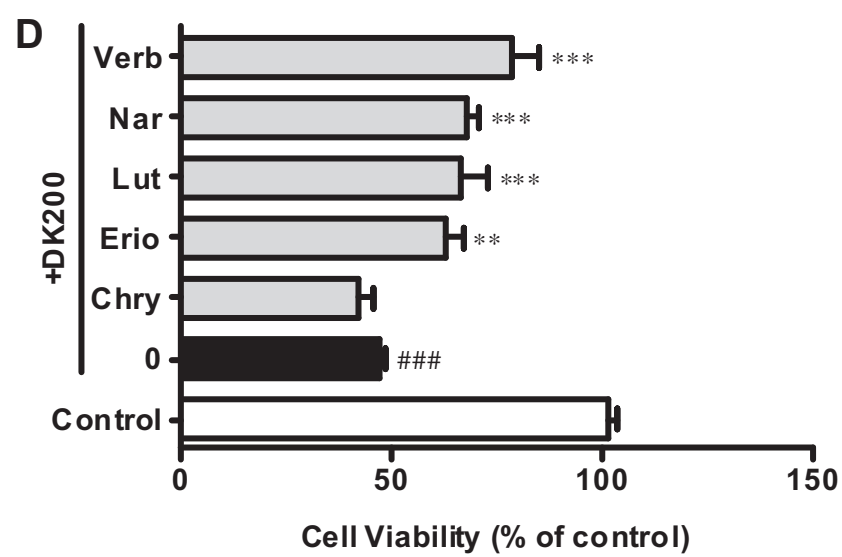

Fig. 4 - Protective effect of the individual standard compounds $(50 \mu \mathrm{g} / \mathrm{mL})$ on intracellular ROS production (A, B) or cells viability (C, D) of human hepatoblastoma HepG2 cells at basal (A and C) $(\square$ ) or under toxic conditions (B, D) induced with potassium dichromate (DK) at $5 \mu \mathrm{M}$ for $48 \mathrm{~h}(\mathrm{~B}, \mathrm{D})$ or at $200 \mu \mathrm{M}$ for $6 \mathrm{~h}(\mathrm{D}$,$) ). The black columns ( \square$ ) represented the incubation of HepG2 cells with DK alone. Values are means \pm S.E.M. of percentage of ROS production or cell viability versus control from 3-4 independent experiments performed at least in triplicate. Api, apigenin; Chry, chrysin; Eri, eriodictyol; Lut, luteolin; Nar, naringenin; Quer, quercetin; R Ac, rosmarinic acid; Ver, verbascoside. Statistical analysis was performed by one-way ANOVA, followed by Dunnett's post hoc test. ${ }^{*} p<0.05 ;{ }^{* *} p<0.01,{ }^{* * *} p<0.001$ when compared to cells exposed to DK $(\square)$ in the absence of individual standard compounds; ${ }^{\# p}<0.05 ;{ }^{\# \#} p<0.01$; ${ }^{\# \# \#} p<0.001$ when compared to untreated cells (control).

glutathione peroxidase in liver (Shati \& Elsaid, 2009). To our knowledge, liver bioprotection has not been previously exploited for Lamium plant extracts.

3.3. Relation between phytochemical content, antioxidant activities and cytoprotective effects

In order to determine the contribution of individual standard PPCs on the previously mentioned beneficial properties of the purified ethanolic extracts, ROS and MTT experiments were also performed for the majority of their individual phenolic constituents. As stated in the material and methods section, the C. multiflorus purified extract mainly contains chrysin derivatives and other flavones enclosing glycosidic derivatives of luteolin, apigenin and quercetin (Table 1). L. album purified ethanol extract is mainly composed of verbascoside, while other phenolics enclose derivatives of apigenin, luteolin and naringenin (Table 1) and major phenolic components in $\mathrm{T}$. citriodorus extract are luteolin-O-glucosides and rosmarinic acid, while it contained minor amounts of eriodictyol and apigenin derivatives (Table 1). Accordingly, apigenin, chrysin, eri- odictyol, quercetin, luteolin, naringenin, rosmarinic acid and verbascoside (all at $50 \mu \mathrm{g} / \mathrm{mL}$ ) were assessed for protection both in basal and under potassium dichromate-induced toxic conditions. Some of these compounds had been previously tested in HepG2 cells and in HepG2/C3A (a clonal derivative of HepG2), showing no cytotoxicity after incubation with the same range of concentrations for $72 \mathrm{~h}$ (Liu, Flynn, Ferguson, Hoagland, \& Yu, 2011).

As can be observed in Fig. 4A, HepG2 cell exposure to quercetin, eriodictyol and naringenin in the absence of potassium dichromate decreased the basal intracellular ROS production by about $63 \%$, $62 \%$ and $38 \%$, respectively. Moreover, under stress conditions, all target PPCs $(50 \mu \mathrm{g} / \mathrm{mL})$ showed high ability to scavenge HepG2 intracellular ROS (Fig. 4B). From all the PPCs tested, flavonoids were the most efficient standard compounds. Indeed, the 3- and 5-hydroxyl groups with a 4-oxo function in $\mathrm{A}$ and $\mathrm{C}$ rings of the flavonol quercetin and the C2-C3 double bond with a 4-oxo function in C ring, common to all of them, are crucial structural characteristics in determining the antioxidant properties of PPCs. Additionally, the presence of an ortho-dihydroxy (3', 4'-OH) structure on the 
B-ring (catechol group), present in quercetin and luteolin, are important to improve the antioxidant properties (Dai \& Mumper, 2010). Besides these two compounds, the flavanone eriodictyol also showed high ROS scavenging capacity (about $50 \%$ ). This fact is in accordance with previous literature data reporting a powerful antioxidant potential of this compound in several cellular models, including neuronal cell cultures, monocytes and retinal pigment epithelial ARPE-19 cells (Cho et al., 2012). One curious finding is the increase of ROS production caused by chrysin (Fig. 4A), suggesting that at that concentration, this compound can induce some toxicity in human hepatoblastoma HepG2 cells, a phenomena described for other antioxidant compounds (Crispo et al., 2010). Despite this, under oxidative stress conditions, this flavone showed high ROS scavenging protection (approximately 53\% ROS reduction in comparison to the control) (Fig. 4B).

Taking into account the amount of the individual PPCs in the purified ethanolic extracts and also their individual capacity in decreasing ROS production under oxidative stress conditions (Fig. 4B), it is possible to suggest that chrysin $(56 \%$ of the total phenolics in C. multiflorus purified ethanolic extract) is the main responsible for its high ROS scavenging capacity. Still note that, despite being present in lower amounts in the C. multiflorus ethanolic extract, luteolin and apigenin also should positively contribute for its antioxidant activities, since they also have high ROS scavenging capacity. Importantly, these latter compounds plus naringenin must for sure be taken into account when considering the ROS scavenging ability of L. album purified ethanolic extract. Despite their minor abundance in the purified ethanolic extract in comparison to verbascoside (54\% total phenolics), they exhibited almost twice of its capacity for decreasing potassium dichromate-stimulated increment of ROS levels. In turn, luteolin, apigenin and eriodictyol are the compounds mainly associated to the ROS scavenging ability of the T. citriodorus ethanolic extract.

Cytoprotective effects of individual phenolics, as measured by the MTT test, were investigated for the most abundant PPCs in each purified ethanolic extract (chrysin, verbascoside and luteolin) and also in the flavanones naringenin and eriodictyol, due to their high ROS scavenging properties. As shown in Fig. 4C, in the absence of potassium dichromate, none of the target standard compounds induced a significant decrease on the cell MTT reducing ability, indicating that at the concentration of $50 \mu \mathrm{g} / \mathrm{mL}$ and for a period treatment of $6 \mathrm{~h}$, all compounds are safe for the HepG2 cells. In good agreement with these results, verbascoside, naringenin, luteolin and eriodictyol counteracted the decrease in cell reducing activity induced by potassium dichromate at $200 \mu \mathrm{M}$ (Fig. 4D) by $49 \%, 28 \%, 26 \%$ and $19 \%$, respectively. Indeed, this protective effect was not only observed for the chrysin treatment.

The herein obtained results also suggest that the cytoprotective effects of L. album and T. citriodorus ethanolic extracts are closely related to their major phenol compounds (verbascoside and luteolin, respectively), in opposition to that observed for the C. multiflorus ethanolic extract. Curiously, the mechanism of cytoprotection of verbascoside, the one exhibiting the highest cytoprotective action, is not totally related to its ROS scavenging action, since this was lower than that of the remaining PPCs (Fig. 4B). Hence, other mechanisms of protection should be investigated in the future for the L. album phenolic extract. Attending that potassium dichromateinduced cytotoxicity engages a cascade of cellular events, enclosing DNA breakdown and the induction of apoptosis through caspases activation (He, Lin, Chen, Zhang, \& Ma, 2007; Son et al., 2010), and that the inhibition of some of these events has been previously associated to verbascoside (Fu, Pang, \& Wong, 2008), these are potential mechanisms involved in the cytoprotective action of L. album phenolic extract.

\section{Conclusion}

C. multiflorus and L. album purified ethanolic extracts are good antioxidants. Their high capacities in counteracting ROS formation in oxidative stress conditions in HepG2 cells are in good agreement with the ROS-scavenging activities of the PPCs present in the extracts. The cytoprotective effect of L. album purified ethanolic extract seems related to the presence of verbascoside, which exhibited the highest cytoprotective action from all the PPCs tested. Since the cytoprotective effect seems to be related to a ROS-independent scavenging action, the mechanisms involved in the cytoprotective action of $\mathrm{L}$. album extract should be investigated. Overall, our results suggest that PPCs play an important role in the beneficial properties of these plants.

\section{Conflict of interest statement}

The authors declare that there are no conflicts of interest.

\section{Acknowledgements}

The authors acknowledge the financial support provided by the FCT to CERNAS (project PEst-OE/AGR/UI0681/2011). Olivia R. Pereira was supported by a PhD grant (SFRH/PROTEC/49600/ 2009). This study was also supported in part by the Ministerio de Ciencia e Innovación (Grant SAF2010-15517); the Instituto de Salud Carlos III, FIS (Grant PI11/00337) and the Junta de Castilla y León (Grants SA023A11-2, SA070A11-2 and BIO/03/ SA23/11), Spain.

\section{R E F E R E N C E S}

Ahmed, W. S., Mohamed, M. A., El-Dib, R. A., \& Hamed, M. M. (2009). New triterpene saponins from Duranta repens Linn. and their cytotoxic activity. Molecules, 14, 1952-1965.

Armatu, A., Colceru-Mihul, S., Bubueanu, C., Draghici, E., \& Pirvu, L. (2010). Evaluation of antioxidant and free scavenging potential of some Lamiaceae species growing in Romania. Romanian Biotechnological Letters, 15, 5274-5280.

Barros, L., Cabrita, L., Boas, M. V., Carvalho, A. M., \& Ferreira, I. C. F. R. (2011). Chemical, biochemical and electrochemical assays to evaluate phytochemicals and antioxidant activity of wild plants. Food Chemistry, 127, 1600-1608.

Briz, O., Serrano, M. A., Macias, R. I. R., \& Marin, J. J. G. (2000). Overcoming cisplatin resistance in vitro by a free and 
liposome-encapsulated bile acid derivative: Bamet-R2. International Journal of Cancer, 88, 287-292.

Chen, Z.-Y., Ma, K. Y., Liang, Y., Peng, C., \& Zuo, Y. (2011). Role and classification of cholesterol-lowering functional foods. Journal of Functional Foods, 3, 61-69.

Cho, N., Choi, J. H., Yang, H., Jeong, E. J., Lee, K. Y., Kim, Y. C., \& Sung, S. H. (2012). Neuroprotective and anti-inflammatory effects of flavonoids isolated from Rhus verniciflua in neuronal HT22 and microglial BV2 cell lines. Food and Chemical Toxicology, 50, 1940-1945.

Crispo, J. A. G., Ansell, D. R., Piche, M., Eibl, J. K., Khaper, N., Ross, G. M., \& Tai, T. C. (2010). Protective effects of polyphenolic compounds on oxidative stress-induced cytotoxicity in PC12 cells. Canadian Journal of Physiology and Pharmacology, 88, 429-438.

Dai, J., \& Mumper, R. J. (2010). Plant phenolics: Extraction, analysis and their antioxidant and anticancer properties. Molecules, 15, 7313-7352.

D'Archivio, M., Filesi, C., Vari, R., Scazzocchio, B., \& Masella, R. (2010). Bioavailability of the polyphenols: Status and controversies. International Journal of Molecular Sciences, 11, 1321-1342.

Deng, G. F., Lin, X., Xu, X. R., Gao, L. L., Xie, J. F., \& Li, H. B. (2013). Antioxidant capacities and total phenolic contents of 56 vegetables. Journal of Functional Foods, 5, 260-266.

Fu, G., Pang, H., \& Wong, Y. H. (2008). Naturally occurring phenylethanoid glycosides: Potential leads for new therapeutics. Current Medicinal Chemistry, 15, 2592-2613.

Gião, M. S., Gonzalez-Sanjose, M. L., Rivero-Perez, M. D., Pereira, C. I., Pintado, M. E., \& Malcata, F. X. (2007). Infusions of Portuguese medicinal plants: Dependence of final antioxidant capacity and phenol content on extraction features. Journal of the Science of Food and Agriculture, 87, 2638-2647.

Hanlon, P. R., Robbins, M. G., Hammon, L. D., \& Barnes, D. M. (2009). Aqueous extract from the vegetative portion of Spanish black radish (Raphanus sativus L. var. niger) induces detoxification enzyme expression in HepG2 cells. Journal of Functional Foods, 1, 356-365.

He, X., Lin, G. X., Chen, M. G., Zhang, J. X., \& Ma, Q. (2007). Protection against chromium (VI)-induced oxidative stress and apoptosis by Nrf2. Recruiting Nrf2 into the nucleus and disrupting the nuclear Nrf2/Keap1 association. Toxicological Sciences, 98, 298-309.

Hossain, M. B., Patras, A., Barry-Ryan, C., Martin-Diana, A. B., \& Brunton, N. P. (2011). Application of principal component and hierarchical cluster analysis to classify different spices based on in vitro antioxidant activity and individual polyphenolic antioxidant compounds. Journal of Functional Foods, 3, 179-189.

Jabri-Karoui, I., Bettaieb, I., Msaada, K., Hammami, M., \& Marzouk, B. (2012). Research on the phenolic compounds and antioxidant activities of Tunisian Thymus capitatus. Journal of Functional Foods, 4, 661-669.

Kirby, A. J., \& Schmidt, R. J. (1997). The antioxidant activity of Chinese herbs for eczema and of placebo herbs. Journal of Ethnopharmacology, 56, 103-108.

Krishnaiah, D., Sarbatly, R., \& Nithyanandam, R. (2011). A review of the antioxidant potential of medicinal plant species. Food and Bioproducts Processing, 89, 217-233.

Liu, Y., Flynn, T. J., Ferguson, M. S., Hoagland, E. M., \& Yu, L. (2011). Effects of dietary phenolics and botanical extracts on hepatotoxicity-related endpoints in human and rat hepatoma cells and statistical models for prediction of hepatotoxicity. Food and Chemical Toxicology, 49, 1820-1827.

Luis, A., Domingues, F., \& Duarte, A. P. (2011). Bioactive compounds, RP-HPLC analysis of phenolics, and antioxidant activity of some Portuguese shrub species extracts. Natural Product Communications, 6, 1863-1872.
Luis, A., Domingues, F., Gil, C., \& Duarte, A. P. (2009). Antioxidant activity of extracts of Portuguese shrubs: Pterospartum tridentatum, Cytisus scoparius and Erica spp. Journal of Medicinal Plants Research, 3, 886-893.

Mersch-Sundermann, V., Knasmuller, S., Wu, X.-j., Darroudi, F., \& Kassie, F. (2004). Use of a human-derived liver cell line for the detection of cytoprotective, antigenotoxic and cogenotoxic agents. Toxicology, 198, 329-340.

Omidbaigi, R., Sefidkon, F., \& Hejazi, M. (2005). Essential oil composition of Thymus citriodorus L. cultivated in Iran. Flavour and Fragrance Journal, 20, 237-238.

Paduch, R., Wójciak-Kosior, M., \& Matysik, G. (2007). Investigation of biological activity of Lamii albi flos extracts. Journal of Ethnopharmacology, 110, 69-75.

Pereira, O. R., Domingues, M. R. M., \& Cardoso, S. M. (2010). Thymus citriodorus: Phenolic characterization and antioxidant activity. In Paper presented at the XXV The International Conference On Polyphenols.

Pereira, O. R., Domingues, M. R. M., Silva, A. M. S., \& Cardoso, S. M. (2012b). Phenolic constituents of Lamium album: Focus on isoscutellarein derivatives. Food Research International, 48, 330-335.

Pereira, O. R., Silva, A. M. S., Domingues, M. R. M., \& Cardoso, S. M. (2012a). Identification of phenolic constituents of Cytisus multiflorus. Food Chemistry, 131, 652-659.

Raja, S., Ahamed, H. N., Kumar, V., Mukherjee, K., Bandyopadhyay, A., \& Mukherjee, P. K. (2007a). Exploring the effect of Cytisus Scoparius on markers of oxidative stress in rats. Iranian Journal of Pharmacology \& Therapeutics, 6, 15-21.

Raja, S., Ahamed, K., Kumar, V., Mukherjee, K., Bandyopadhyay, A., \& Mukherjee, P. K. (2007b). Antioxidant effect of Cytisus scoparius against carbon tetrachloride treated liver injury in rats. Journal of Ethnopharmacology, 109, 41-47.

Sanchez-Valle, V., Chavez-Tapia, N. C., Uribe, M., \& MendezSanchez, N. (2012). Role of oxidative stress and molecular changes in liver fibrosis: A review. Current Medicinal Chemistry, $18,18$.

Shati, A. A., \& Elsaid, F. G. (2009). Effects of water extracts of thyme (Thymus vulgaris) and ginger (Zingiber officinale Roscoe) on alcohol abuse. Food and Chemical Toxicology, 47, 1945-1949.

Son, Y. O., Hitron, J. A., Wang, X., Chang, Q. S., Pan, J. J., Zhang, Z., Liu, J. K., Wang, S. X., Lee, J. C., \& Shi, X. L. (2010). Cr(VI) induces mitochondrial-mediated and caspase-dependent apoptosis through reactive oxygen species-mediated p53 activation in JB6 Cl41 cells. Toxicology and Applied Pharmacology, 245, 226-235.

Valyova, M. S., Dimitrova, M. A., Ganeva, Y. A., Mihova KapchinaToteva, V., \& Petkova Yordanova, Z. (2011). Evaluation of antioxidant and free radical scavenging potential of Lamium album L. growing in Bulgaria. Journal of Pharmacy Research, 4, 945-947.

Wang, B.-S., Lee, C. P., Chen, Z.-T., Yu, H. M., \& Duh, P.-D. (2012). Comparison of the hepatoprotective activity between cultured Cordyceps militaris and natural Cordyceps sinensis. Journal of Functional Foods, 4, 489-495.

Yee, S. B., Lee, J. H., Chung, H. Y., Im, K. S., Bae, S. J., Choi, J. S., \& Kim, N. D. (2003). Inhibitory effects of luteolin isolated from Ixeris sonchifolia Hance on the proliferation of HepG2 human hepatocellular carcinoma cells. Archives of Pharmacal Research, 26, 151-156.

Yen, G. C., \& Duh, P. D. (1994). Scavenging effect of methanolic extracts of peanut hulls on free-radical anda active-oxygen species. Journal of Agricultural and Food Chemistry, 42, 629-632.

Zakaria, Z. A., Rofiee, M. S., Teh, L. K., Salleh, M. Z., Sulaiman, M. R., \& Somchit, M. N. (2011). Bauhinia purpurea leaves' extracts exhibited in vitro antiproliferative and antioxidant activities. African Journal of Biotechnology, 10, 65-74. 